\title{
Herbal Medicines Used During the First Trimester and Major Congenital Malformations An Analysis of Data from a Pregnancy Cohort Study
}

\author{
Chao-Hua Chuang, 1,2 Pat Doyle, ${ }^{3}$ Jung-Der Wang, ${ }^{1,4}$ Pei-Jen Chang, Jung-Nien Lai, \\ and Pau-Chung Chen ${ }^{1}$ \\ 1 Institute of Occupational Medicine and Industrial Hygiene, National Taiwan University \\ College of Public Health, Taipei, Taiwan \\ 2 Department of Nursing, Fooyin University, Kaohsiung County, Taiwan \\ 3 Department of Epidemiology and Population Health, London School of Hygiene and Tropical \\ Medicine, London, UK \\ 4 Department of Internal Medicine, National Taiwan University Hospital, Taipei, Taiwan \\ 5 Department of Nursing, National Taipei College of Nursing, Taipei, Taiwan \\ 6 Division of Gynecology, Traditional Chinese Medicine, Taipei City Hospital, Taipei, Taiwan
}

\section{Abstract}

Background: Major congenital malformations place a considerable burden on the affected child, the family and society. Any kind of medicine used during pregnancy might have a harmful impact; therefore, such practice has raised concerns. The objective of the current study was to explore the relationship between the use of herbal medicines by pregnant women during the first trimester of pregnancy and the risk of major congenital malformation in their live born infants.

Methods: This was a cross-sectional analysis of data from a prospective pregnancy cohort, which was established between 1984 and 1987. To assemble the cohort, pregnant women of $\geq 26$ weeks of gestation who came to the Taipei Municipal Maternal and Child Hospital in Taiwan for prenatal care were enrolled in the study and interviewed using a structured questionnaire. Detailed information, including herbal medicine use during different periods of pregnancy, was obtained during the interview. Past medical history, current obstetric data and details on conventional medicines used during pregnancy were abstracted from medical records. Data on birth weight, gestational duration and characteristics of live born infants were gathered from the Taiwan national birth register. Congenital malformation information was obtained from multiple sources: the newborn examination record (1984-7); the national death register (1984-2003); and Taiwan National Health Insurance data (1996-2000). Multiple logistic regression was used to estimate the odds ratio $[\mathrm{OR}]$ of major congenital malformation by herbal medicines used during the first trimester.

Results: A total of 14551 live births were analysed. After adjustment for confounding factors, taking huanglian during the first trimester of pregnancy was found to be associated with increased risk of congenital malformations of the 
nervous system (adjusted OR 8.62, 95\% CI 2.54, 29.24). An-Tai-Yin was associated with an increased risk of congenital malformations of the musculoskeletal and connective tissues (adjusted OR 1.61, 95\% CI 1.10, 2.36) and the eye (adjusted OR 7.30, 95\% CI 1.47, 36.18).

Conclusion: We found evidence for a possible link between the use of specific herbal medicines during the first trimester of pregnancy and increased risks of specific groups of congenital malformations. We could not investigate whether the adverse effects were related to direct toxicity from the herbal medicines, or were from misuse, contamination or uncontrolled confounding. Nonetheless, we would advise caution regarding use of herbal medicines during pregnancy, and we suggest that further investigation of these findings is warranted.

\section{Background}

Major congenital malformations occur in approximately $3 \%$ of live births, ${ }^{[1,2]}$ placing a considerable burden on the affected child, the family and society. The embryonic period, from the second to the eighth week of gestation, is the critical window of vulnerability for the developing fetus when exposure to harmful agents such as drugs, chemical and biological agents, and radiation, ${ }^{[3]}$ as well as nutritional deficiencies, ${ }^{[4]}$ may cause structural malformations. There are also other risk factors related to congenital anomalies such as multiple births, ${ }^{[5]}$ consanguinity, ${ }^{[6]}$ maternal life-event stress $^{[7]}$ and premature birth. ${ }^{[8]}$

The use of herbal medicine is common in Tai$\operatorname{wan}^{[9,10]}$ and is gaining popularity worldwide, ${ }^{[11-13]}$ including its use during pregnancy. ${ }^{[14-19]}$ Because of the potential harmful impact of any kind of medicine during pregnancy, such practice has raised concerns among public health practitioners and consumers regarding benefit and risk. ${ }^{[15,19]}$ Numerous studies of maternal drug consumption during pregnancy have been carried out over the last few decades. ${ }^{[20-24]}$ However, most have dealt with prescription drugs and conventional medication and there is a general lack of evidence for safety and efficacy regarding the use of herbal medicines during pregnancy. The few published studies on this topic have concluded that echinacea or raspberry leaf used during preg- nancy seemed to produce no adverse effects for either the mother or fetus; ${ }^{[25,26]}$ however, a local herbal medicine from South Africa used in labour resulted in an increased rate of fetal distress. ${ }^{[27]}$

Several review articles have shown inconclusive results for a variety of herbs used for different purposes in pregnancy. ${ }^{[28,29]}$ Several animal studies have demonstrated potential adverse effects of herbal medicines in pregnancy. The administration of berberine chloride dehydrate (berberine is the main component of huanglian) to rats during pregnancy decreased fetal weight. ${ }^{[30]}$ Ginseng was found to be teratogenic for rat embryos, ${ }^{[31]}$ and some traditional Chinese medicines demonstrated inhibition of early mouse embryogenesis. ${ }^{[32]}$ Besides the direct toxicity of herbal material, ${ }^{[33]}$ issues to consider in any study include contamination by microbes, heavy metals, pesticides or even adulteration with Western medicines, which may confound the potential herbal toxicity. ${ }^{[34-37]}$

Although the safety and efficacy of herbal medicines remain largely unassessed, their use is becoming increasingly fashionable in Western countries. ${ }^{[38]}$ Critical assessment of their safety and efficacy is an urgent necessity. The aim of this study was to explore the relationship between the use of herbal medicines during the first trimester of pregnancy and the risk of major congenital malformation. 


\section{Methods}

\section{Study Population and Data Collection}

The pregnancy cohort comprised pregnant woman of $\geq 26$-weeks gestation who came to the Taipei Municipal Maternal and Child Hospital (TMMCH) for prenatal care between September 1984 and June 1987. A structured questionnaire was used to prospectively obtain detailed information regarding the use of herbal medicines during different pregnancy periods, gynaecological and obstetric history, and various demographic variables relating to family life. The interviews were conducted in the third trimester of pregnancy by the same three interviewers. The medical records of each mother were then reviewed by the same medical assistant to extract pertinent information on their medical history and use of conventional medicines during pregnancy.

Data on birth weight, gestation duration, and characteristics of live born infants were gathered from the Taiwan national birth register (for births 1984-7). Congenital malformation information was obtained from several sources. First, information was extracted from the newborn examination and medical records for births during 1984-7. The other sources of congenital malformation data were national death registrations for the period 1984-2003 and Taiwan National Health Insurance data on critical illness and injury registration during 1996-2000. We used the national identification number (ID) of mothers to link them to the Taiwan national birth registration, and were able to obtain the ID of their children. Using the ID of the child, we then searched the national death registration and National Health Insurance data on critical illness and injury registration to obtain malformation information.

All study participants provided informed consent, which was approved by the National Taiwan University College of Public Health Ethic Review Board.

\section{Variables}

Data on age, education, occupation and family income were obtained from the interview question- naire. Education was stratified into four groups: university and college or above, senior high school, junior high school, and primary school and below. Classifications of occupation were made according to the modified Taiwanese version of the International Classification of Occupations, and were later summarised into four groups: non-manual, manual, housewives and other occupations. Family income was defined as the total parental monthly income (US\$1 $\approx$ NT $\$$ [new Taiwan dollar]33, in 2004) with four categories: $\quad \geq 40001, \quad 30001-40000$, $20001-30000$ and $\leq 20000$ per month.

Previous gynaecological and obstetric histories were obtained from the interview questionnaire. Obstetric and perinatal outcomes included previous spontaneous abortion, stillbirth or neonatal death, previous low birth weight or preterm delivery. Gynaecological history included diseases related to the uterus, ovary or fallopian tube, and infertility. Medical histories of diabetes mellitus, hypertension or antepartum haemorrhage, as well as conventional medicine use during pregnancy, were extracted from the mothers' medical records.

Information on the use of herbal medicines and vitamin and iron supplements during the prenatal period was obtained from questionnaires on prenatal care visits. For the purposes of this study, a herbal medicine is defined as any botanical product or preparation with presumed therapeutic or other human health benefits that contains either raw or processed ingredients from one or more plants. ${ }^{\left[{ }^{39]}\right.}$ In traditional Chinese medicine, materials of inorganic or animal origin may also be present.

Major congenital malformations were defined as those that can adversely affect the health and development of the infant. They were categorised according to the 9th edition of the International Classification of Diseases (ICD-9) list of congenital malformation, as described in the Eurocat Guide 1.2.[40] The exclusion criteria were chromosomal anomalies, minor congenital malformations, small case numbers, or non-significant statistic. We examined 12 categories of congenital malformation, relating to: other nervous system, neural-tube defects, eye, ear, heart, cleft lip with or without cleft palate, cleft 
Table I. International Classification of Diseases - 9th edition (ICD-9) codes for the categories of major congenital malformations used in the study

\begin{tabular}{ll}
\hline $\begin{array}{l}\text { Category of } \\
\text { malformation }\end{array}$ & ICD-9 code \\
\hline $\begin{array}{l}\text { Other nervous } \\
\text { system }\end{array}$ & $742.1-742.5,742.8,742.9$ \\
Neural-tube defects & $740.0-740.2,741.0-741.9,742.0$ \\
Eye & $743.0-743.6$ [excl. 743.65] 743.8-743.9 \\
Ear & $744.0-744.2$ [excl. 744.11, 744.12] \\
Heart & $745.0-745.9,746.0-746.9,747.0-747.4$ \\
& [excl. 747.0 $\left.{ }^{\circ}\right]$ \\
Cleft lip with or & $749.1-749.2$ \\
without cleft palate & \\
Cleft palate & 74.0 \\
Digestive system & $750.3-750.5,750.7-751.9$ \\
Internal urogenital & $752.0-752.3,752.9,753.0-753.9$ \\
system & \\
$\begin{array}{l}\text { External genital } \\
\text { system }\end{array}$ & $752.4-752.8$ [excl. 752.5] \\
$\begin{array}{l}\text { Musculoskeletal and } \\
\text { connective tissues }\end{array}$ & $744.5,754.0$ \\
Limbs & $754.4-754.7$ [excl. 754.52, 754.60, 754.73], \\
\hline $\begin{array}{l}\text { a Patient ductus arteriosus in preterm/low birth weight babies. } \\
\text { excl. = excluding. }\end{array}$ & \\
\hline
\end{tabular}

palate, digestive system, internal urogenital system, external genital system, musculoskeletal and connective tissues, and limbs. A full list of ICD-9 codes is given in table I.

There were several categories of herbal medicines used during the first trimester, including An-Tai-Yin, huanglian, ginseng, Ba-Zhen-Tang, Szu-Wu-Tang, Dang-Gui-Saho-Yao-San and others. ${ }^{[9]}$ Our final grouping for analysis was based on frequency of use and consisted of An-Tai-Yin alone, huanglian alone, ginseng alone, and others. Other herbs either in single or combined use included any herbs except for An-Ti-Yin, huanglian and ginseng.

\section{Analyses}

Multiple logistic regression was used to estimate odds ratios [ORs] for each of the 12 categories of congenital malformation in live born children according to the usage of different herbal medicines during the first trimester of pregnancy. A $10 \%$ change-in-estimate method was used to assess po- tential confounders. ${ }^{[41]}$ It is the method that selects a variable for control only if its control produces $>10 \%$ change in a rate ratio estimate of interest.

Potential confounding variables included characteristics of the mothers (age, education, occupation, body height and pre-pregnant bodyweight); characteristics of the fathers (age, education, occupation and family income); characteristics of the infants themselves (number, sex, parity and gestational age); obstetric history and maternal exposures during pregnancy (previous histories of gynaecological diseases, previous low birth weight or preterm delivery, previous spontaneous abortion, chronic diseases, diabetes, hypertension, antepartum haemorrhage, medicines used during pregnancy, vitamin or iron supplements, fever $>38^{\circ} \mathrm{C}$, microwave oven use, $\mathrm{x}$ ray radiography used, stressful events, general anaesthesia used, chemical exposure in the workplace, laboratory work, cigarette smoking, alcohol intake during the first trimester); paternal exposures during the 1-year period before his partner's current pregnancy (long-term medication taken, chemical exposure, $\mathrm{x}$-ray radiography use, cigarette smoking, alcohol intake, general anaesthesia); and history of congenital malformation in the parents and relatives. Statistical analysis was performed using SPSS for Windows, Release 11.0.

\section{Results}

A total of 14551 live births were included in the study population. The mothers represented approximately $80 \%$ of pregnant women accepting prenatal care at our study hospital between 1984 and 1987.

The majority of parents were 20-34 years old with a senior high school education, a non-manual occupation and a monthly family income of NT\$20 001-30 000 (table II). Compared with the national census data during the period of 1984-7 in Taiwan, ${ }^{[42]}$ our sample seemed to have a higher proportion of women with a senior high school education or above $(73.2 \%$ vs $34.7 \%)$, employment $(67.1 \%$ vs $45.4 \%)$ and professional job $(8.5 \%$ vs $0.5 \%$ ). The study participants were of higher socioeconomic status than the average Taiwanese citizen. The majority of pre-pregnant bodyweights and 
Table II. Percentages of live born children stratified by parental characteristics

\begin{tabular}{|c|c|c|c|c|c|c|c|c|}
\hline \multirow[t]{3}{*}{ Characteristic } & \multicolumn{4}{|l|}{ Mother } & \multicolumn{4}{|l|}{ Father } \\
\hline & \multicolumn{2}{|c|}{$\begin{array}{l}\text { herbal medicines } \\
\text { used }\end{array}$} & \multicolumn{2}{|c|}{$\begin{array}{l}\text { had child with } \geq 1 \text { major } \\
\text { congenital malformation }\end{array}$} & \multicolumn{2}{|c|}{$\begin{array}{l}\text { herbal medicines } \\
\text { used }\end{array}$} & \multicolumn{2}{|c|}{$\begin{array}{l}\text { had child with } \geq 1 \text { major } \\
\text { congenital malformation }\end{array}$} \\
\hline & no & yes & no & yes & no & yes & no & yes \\
\hline $\begin{array}{l}\text { Total number of } \\
\text { children }\end{array}$ & 12092 & 2459 & 14102 & 449 & 12092 & 2459 & 14102 & 449 \\
\hline \multicolumn{9}{|l|}{ Age (years) } \\
\hline$\leq 19$ & 1.3 & 1.1 & 1.3 & 0.9 & 0.3 & $0.2^{*}$ & 0.3 & 0.2 \\
\hline $20-34$ & 95.7 & 96.7 & 95.9 & 96.0 & 89.8 & 91.4 & 87.6 & 86.9 \\
\hline$\geq 35$ & 3.0 & 2.2 & 2.8 & 3.1 & 9.9 & 8.4 & 12.1 & 12.9 \\
\hline \multicolumn{9}{|l|}{ Education } \\
\hline $\begin{array}{l}\text { elementary school } \\
\text { or below }\end{array}$ & 9.7 & 10.7 & 9.9 & 8.2 & 6.8 & 6.8 & 6.8 & 6.5 \\
\hline junior high school & 15.5 & 16.8 & 15.6 & 19.6 & 12.8 & 13.3 & 12.9 & 12.7 \\
\hline senior high school & 50.8 & 49.7 & 50.7 & 49.5 & 41.0 & 42.4 & 41.3 & 38.3 \\
\hline university or above & 24.0 & 22.8 & 23.8 & 22.7 & 39.4 & 37.6 & 39.0 & 42.5 \\
\hline \multicolumn{9}{|l|}{ Occupation } \\
\hline non-manual & 46.1 & $47.8^{\star *}$ & 46.4 & 45.9 & 67.5 & 68.0 & 67.6 & 65.8 \\
\hline manual & 17.9 & 21.5 & 18.4 & 21.6 & 29.7 & 29.6 & 29.6 & 31.8 \\
\hline housewives & 36.0 & 30.7 & 35.2 & 32.5 & & & & \\
\hline other & & & & & 2.8 & 2.4 & 2.8 & 2.4 \\
\hline \multicolumn{9}{|l|}{ Body height $(\mathrm{cm})$} \\
\hline$\leq 150$ & 10.3 & 10.6 & 10.3 & 12.5 & & & & \\
\hline $151-155$ & 24.6 & 25.4 & 24.8 & 23.4 & & & & \\
\hline $156-160$ & 42.4 & 42.5 & 42.5 & 40.3 & & & & \\
\hline$>160$ & 22.7 & 21.6 & 22.5 & 23.8 & & & & \\
\hline \multicolumn{9}{|c|}{ Pre-pregnant weight $(\mathrm{kg})$} \\
\hline$\leq 45$ & 25.0 & $30.4^{\star *}$ & 25.9 & 27.4 & & & & \\
\hline $46-50$ & 36.2 & 34.6 & 36.0 & 35.0 & & & & \\
\hline $51-55$ & 23.2 & 21.0 & 22.8 & 22.3 & & & & \\
\hline$\geq 56$ & 15.6 & 14.0 & 15.3 & 15.4 & & & & \\
\hline \multicolumn{9}{|c|}{ Family income (NT\$ per month)a } \\
\hline$\leq 20000$ & 25.7 & 28.1 & 26.0 & 29.6 & & & & \\
\hline $20001-30000$ & 45.3 & 44.0 & 45.2 & 42.8 & & & & \\
\hline $30001-40,000$ & 18.9 & 19.0 & 18.9 & 19.6 & & & & \\
\hline$\geq 40001$ & 10.1 & 8.9 & 9.9 & 8.0 & & & & \\
\hline
\end{tabular}

a Values refer to the joint family income.

NT\$ = new Taiwanese dollar; * $p<0.05 ;{ }^{*} p<0.001$ in Chi-square test.

heights of mothers were in the ranges of $46-50 \mathrm{~kg}$ and $156-160 \mathrm{~cm}$, respectively. In addition, approximately $99 \%$ of infants were singleton and $97 \%$ were carried to full term. Approximately half of the infants were male and first parity (table III).

Overall, $31 \%$ of mothers used medicines during pregnancy and approximately $9 \%$ used vitamin and iron supplements during the first trimester (table IV). Most pregnant women had no previous history of gynaecological diseases, low birth weight or preterm delivery, spontaneous abortion, chronic diseases or fever $>38^{\circ} \mathrm{C}$ during the first trimester. Less than $1 \%$ of mothers experienced diabetes, hypertension, or antepartum haemorrhage during pregnancy. Exposure to a microwave oven, x-ray radiography, stressful events, general anaesthesia, chemicals, or laboratory work during the first trimester was not common. Less than $2 \%$ of the mothers smoked 
Table III. Percentage of live born children stratified by their characteristics

\begin{tabular}{|c|c|c|c|c|}
\hline \multirow[t]{2}{*}{ Characteristics } & \multicolumn{2}{|c|}{$\begin{array}{l}\text { Herbal medicines } \\
\text { used by mother }\end{array}$} & \multicolumn{2}{|c|}{$\begin{array}{l}\geq 1 \text { major congenital } \\
\text { malformation }\end{array}$} \\
\hline & no & yes & no & yes \\
\hline $\begin{array}{l}\text { Total number of } \\
\text { children }\end{array}$ & 12092 & 2459 & 14102 & 449 \\
\hline \multicolumn{5}{|l|}{ Number } \\
\hline singleton & 98.7 & $99.0^{*}$ & 98.8 & 98.4 \\
\hline twin & 1.3 & 0.9 & 1.2 & 1.6 \\
\hline triplet or higher & 0.0003 & 0.1 & 0.0005 & \\
\hline \multicolumn{5}{|l|}{ Sex } \\
\hline male & 51.3 & 51.6 & 51.2 & $55.9^{\star}$ \\
\hline female & 48.7 & 48.4 & 48.8 & 44.1 \\
\hline \multicolumn{5}{|l|}{ Parity } \\
\hline 1 & 49.4 & $57.7^{\star \star}$ & 50.6 & $57.2^{*}$ \\
\hline $2-3$ & 48.6 & 40.9 & 47.5 & 41.9 \\
\hline$\geq 4$ & 2.0 & 1.4 & 1.9 & 0.9 \\
\hline \multicolumn{5}{|l|}{ Preterm delivery } \\
\hline no & 96.9 & 96.5 & 96.9 & 97.3 \\
\hline yes & 3.1 & 3.5 & 3.1 & 2.7 \\
\hline
\end{tabular}

during the first trimester of pregnancy and $<1 \%$ drank alcohol.

Very few fathers took long-term medicines, had been exposed to chemicals, $\mathrm{x}$-ray radiography, general anaesthesia or alcohol during the 1-year period before their partners' current pregnancy (table IV). Over half of fathers had smoked before the current pregnancy. Very few congenital malformations were reported for parents or other relatives.

A total of $16.9 \%$ of the children's mothers reported ever-use of any type of herbal medicine during the first trimester of pregnancy (table V). An-TaiYin and huanglian were the most commonly consumed herbal medicines, with prevalences of $11.4 \%$ and $1.5 \%$, respectively. Less than one in 100 mothers $(0.8 \%)$ took ginseng. There was no difference in the pattern of use when the dataset was restricted to mothers who did not have any recorded disease.

A total of $449(3.1 \%)$ children had 469 major malformations (table VI). Since some degree of underestimation of prevalence in registration data is expected, our observed prevalence of approximately $3 \%$ appears reasonably accurate. The five most fre- quent groups were congenital anomalies of the musculoskeletal and connective tissues, external genital system, heart, internal urogenital system and ear. There were no differences in the frequency of reported malformations when the dataset was restricted to mothers with no recorded diseases, such as chronic diseases, fever $>38^{\circ} \mathrm{C}$ during first trimester, hypertension, diabetes or antepartum haemorrhage during pregnancy.

Adjusted ORs for maternal herbal medicine use during the first trimester of pregnancy and major congenital malformations are shown in table VII. After adjustment for confounding factors, taking huanglian during the first trimester of pregnancy was found to be associated with an increased risk of congenital malformation of the nervous system (adjusted OR 8.62, 95\% CI 2.54, 29.24). There were no cases of neural tube defects in the children of women who took huanglian. There was some evidence that huanglian was also associated with an increased risk to the external genital organs (adjusted OR 3.82, $95 \% \mathrm{CI} 1.18,12.40)$, although this finding was less robust when mothers with recorded disease were excluded. An-Tai-Yin was associated with an increased risk of congenital malformations of the musculoskeletal and connective tissues (adjusted OR $1.61,95 \%$ CI 1.10, 2.36) and eye (adjusted OR 7.30, $95 \%$ CI 1.47, 36.18). There were no differences in these findings when mothers with recorded diseases were excluded (table VII).

\section{Discussion}

This study found an association between the use of huanglian and An-Tai-Yin during the first trimester of pregnancy and an increased risk of specific groups of major congenital malformations in the resulting offspring. However, the validity of our study methods needs to be carefully assessed before making any firm conclusions.

We collected detailed information about the ten most commonly used herbal medicines by Taiwanese women in pregnancy. Other herbal medicines were used, but so rarely that we were unable to explore their effect. In particular, we had insufficient power to investigate the effect of gin- 
Table IV. Percentage of liveborn children stratified by parental risk factors

\begin{tabular}{|c|c|c|c|c|}
\hline \multirow[t]{2}{*}{ Risk factors } & \multicolumn{2}{|c|}{ Herbal medicines used by mother } & \multicolumn{2}{|c|}{$\geq 1$ major congenital malformations } \\
\hline & no & yes & no & yes \\
\hline Total number of children & 12092 & 2459 & 14102 & 449 \\
\hline \multicolumn{5}{|l|}{ Mothers } \\
\hline Vitamin or iron supplement used & 8.9 & $12.0^{\star *}$ & 9.4 & 8.9 \\
\hline Medicines used & 30.4 & $35.0^{\star *}$ & 31.1 & 33.2 \\
\hline Previous gynaecological diseases & 8.5 & $11.0^{\star *}$ & 8.9 & 8.0 \\
\hline Previous LBW or PTD & 4.7 & 4.6 & 4.7 & 3.6 \\
\hline Previous spontaneous abortion & 8.0 & $11.5^{\star *}$ & 8.6 & 8.7 \\
\hline Chronic diseases & 0.5 & 0.6 & 0.5 & 0.2 \\
\hline Fever $>38^{\circ} \mathrm{C}$ & 2.7 & $4.1^{\star *}$ & 2.9 & 2.4 \\
\hline Diabetes mellitus & 0.1 & 0.2 & 0.1 & 0.2 \\
\hline Hypertension & 0.6 & 0.8 & 0.6 & $1.8^{* *}$ \\
\hline Antepartum haemorrhage & 0.4 & 0.7 & 0.4 & 0.7 \\
\hline Microwave oven used & 0.9 & 0.9 & 0.9 & 0.7 \\
\hline X-ray radiography used & 1.0 & 0.7 & 0.9 & 0.9 \\
\hline Stressful events & 10.8 & 10.4 & 10.7 & 11.8 \\
\hline General anaesthesia used & 0.0003 & 0.0004 & 0.0004 & \\
\hline Chemical exposure in the workplace & 3.1 & 3.5 & 3.1 & 4.2 \\
\hline Laboratory work & 0.1 & 0.1 & 0.1 & - \\
\hline Cigarette smoking & 1.5 & 1.5 & 1.5 & 1.8 \\
\hline Alcohol drinking & 0.1 & 0.1 & 0.1 & \\
\hline \multicolumn{5}{|l|}{ Fathers } \\
\hline Long-term medication taken & 1.2 & 1.0 & 1.2 & 1.3 \\
\hline Chemical exposure & 8.2 & 7.1 & 8.0 & 8.5 \\
\hline Cigarette smoking & 54.3 & 52.6 & 53.9 & 56.6 \\
\hline Alcohol drinking & 6.0 & 5.4 & 5.8 & 7.1 \\
\hline $\mathrm{X}$-ray radiography used & 8.3 & 8.0 & 8.3 & 8.5 \\
\hline General anaesthesia used & 0.1 & 0.2 & 0.1 & $0.7^{\star}$ \\
\hline \multicolumn{5}{|l|}{ History of congenital malformations } \\
\hline Mother & 0.2 & 0.3 & 0.2 & 0.4 \\
\hline Father & 0.1 & 0.2 & 0.1 & 0.7 \\
\hline Siblings & 1.0 & $0.6^{*}$ & 1.0 & 0.2 \\
\hline Parents' brothers or sisters & 1.5 & 1.4 & 1.5 & 1.3 \\
\hline Cousins & 1.2 & 1.5 & 1.3 & 1.6 \\
\hline
\end{tabular}

seng in pregnancy. We did attempt to analyse the association between congenital malformations and combined use of common herbal medicines such as An-Tai-Yin, huanglian, and ginseng. The results did not show any significant effects, most probably because of low statistical power due to the small numbers of combined exposures and congenital malformations. There were only three cases of nervous system anomalies in children exposed to huanglian, and three cases of eye anomalies in children exposed to An-Tai-Yin. According to the national Taiwan congenital malformation registration data for live born infants in 1993 (the initial year of monitoring), ${ }^{[43]}$ the prevalence rate of congenital malformation of the nervous system and eye was approximately $0.18 \%$ and $0.02 \%$, respectively. The expected numbers of nervous system anomalies in our study population would be about 0.4 and 0.3 , respectively. However, wide confidence intervals 
Table V. Percentages of children whose mother used herbal medicines during the first trimester

\begin{tabular}{lll}
\hline Herbal medicines & $\begin{array}{l}\text { All children's } \\
\text { mothers }(\%) \\
{[\mathrm{n}=14551]}\end{array}$ & $\begin{array}{l}\text { Children of } \\
\text { mothers without } \\
\text { obstetric } \\
\text { complications } \\
(\%)[\mathrm{n}=13 \text { 891] }\end{array}$ \\
\hline Ever use & 16.9 & 16.6 \\
An-Tai-Yin & 11.4 & 11.2 \\
Huanglian & 1.5 & 1.5 \\
Ginseng & 0.8 & 0.8 \\
An-Tai-Yin and huanglian & 0.5 & 0.5 \\
An-Tai-Yin and ginseng & 0.2 & 0.2 \\
Huanglian and ginseng & 0.02 & 0.02 \\
An-Tai-Yin, ginseng and & 0.01 & 0.01 \\
huanglian & & \\
Other herbs & 2.5 & 2.4 \\
\hline
\end{tabular}

a Excluding mothers with chronic diseases, fever $>38^{\circ} \mathrm{C}$ during first trimester, hypertension, diabetes mellitus, or antepartum haemorrhage during pregnancy.

need to be taken into account for interpreting our results, in addition to small numbers.

There were 12 categories of major congenital malformations included in our study. The congenital malformation relating to chromosomes was excluded because there were only nine cases of congenital anomalies of chromosomes, and most of them were Down's syndrome. In general, Down's syndrome is initiated around the time of fertilisation, so the effect of herbal medicines on the occurrence of Down's syndrome could be excluded. Most of the structural congenital malformations occur in the first trimester, so we focused on the effects of hazards on this period.

In general, Western medicines are only used for specific indications during pregnancy, which implies a high correlation between indications and prescribed medicines. However, pregnant women in Taiwan traditionally use most herbal medicines without any specific purpose. The exception is AnTa-Yin, which seemed more likely to be used when there was a previous history of abortion. However, in the multiple logistic regression model, controlling for the possible confounding effect of history of previous abortion did not change the estimate between An-Tai-Yin and musculoskeletal and connective tissues or eye anomalies, suggesting little con- founding by indication of use for specific herbal medicines.

We were concerned about the potential confounding factor of pre-existing disease in the mother, or obstetric complications occurring during pregnancy. For this reason we stratified our subjects into two groups: one group included all pregnant women enrolled in the study, the other included only pregnant women without chronic diseases, fever $>38^{\circ} \mathrm{C}$ during the first trimester, diabetes, hypertension, or antepartum haemorrhage during pregnancy. Apart from the findings for huanglian and malformations of the genital system, the pattern of results was similar in both groups and we are confident that preexisting maternal disease or obstetric complications cannot explain the findings presented here.

We thus conclude that the habit of pregnant women using herbal medicines during pregnancies was associated with increased risk of congenital malformations. We can say little about mechanisms. The adverse effect of herbal medicines might result from direct herbal toxicity, or contamination of herbal medicines from microbes, heavy metals, or pesticides, or even adulteration with Western medicines.

It is important to understand why women take herbal medicines during pregnancy. Traditionally,

Table VI. Percentages of children with $\geq 1$ major congenital malformation

\begin{tabular}{ll}
\hline Malformation category & $\%$ of children $(\mathrm{n}=14551)^{\mathrm{a}}$ \\
\hline Any major congenital malformation & 3.1 \\
Musculoskeletal and connective & 1.3 \\
tissues & \\
External genital system & 0.4 \\
Heart & 0.4 \\
Internal urogenital system & 0.4 \\
Ear & 0.3 \\
Other nervous system & 0.2 \\
Neural-tube defects & 0.04 \\
Limbs & 0.1 \\
Digestive system & 0.1 \\
Cleft lip with or without palate & 0.1 \\
Cleft palate & 0.1 \\
Eye & 0.04 \\
\hline These figures did not change when data from mothers with \\
$\quad$ chronic diseases, fever $>38^{\circ} \mathrm{C}$ during first trimester, \\
$\quad$ hypertension, diabetes mellitus or antepartum haemorrhage \\
$\quad$ during pregnancy were excluded.
\end{tabular}




\begin{tabular}{|c|c|c|c|c|c|c|c|c|c|c|}
\hline & \multicolumn{2}{|c|}{ Never use ${ }^{a}$} & \multicolumn{2}{|c|}{ Ginseng alone } & \multicolumn{2}{|c|}{ Huanglian alone } & \multicolumn{2}{|c|}{ An-Tai-Yin alone } & \multicolumn{2}{|c|}{ Other herbs } \\
\hline & \multirow[t]{2}{*}{$\mathrm{n}$} & \multirow[t]{2}{*}{ OR } & \multirow[t]{2}{*}{$\mathrm{n}$} & \multirow[t]{2}{*}{ OR $(95 \% \mathrm{Cl})$} & \multirow[t]{2}{*}{$\mathrm{n}$} & \multirow[t]{2}{*}{ OR $(95 \% \mathrm{Cl})$} & \multirow[t]{2}{*}{$\mathrm{n}$} & \multirow[t]{2}{*}{ OR $(95 \% \mathrm{Cl})$} & \multirow[t]{2}{*}{$\bar{n}$} & \multirow[t]{2}{*}{ OR $(95 \% \mathrm{Cl})$} \\
\hline $\begin{array}{ll}\frac{1}{\bar{c}} & \text { malformations } \\
0 & \text { All mothers }\end{array}$ & & & & & & & & & & \\
\hline Other nervous system & 20 & 1.00 & 1 & $4.99(0.66,37.47)$ & 3 & $8.62(2.54,29.24)^{\star \star \star}$ & 3 & $1.09(0.32,3.68)$ & 1 & $1.70(0.23,12.67)$ \\
\hline Neural-tube defects & 4 & 1.00 & 0 & & 0 & & 2 & $3.65(0.67,19.92)$ & 0 & \\
\hline External genital system & 45 & 1.00 & 0 & & 3 & $3.82(1.18,12.40)^{\star}$ & 6 & $0.97(0.41,2.28)$ & 0 & \\
\hline $\begin{array}{l}\text { Muscloskeletal and } \\
\text { connective tissues }\end{array}$ & 143 & 1.00 & 4 & $2.52^{\mathrm{b}}(0.91,6.92)$ & 2 & $0.75^{b}(0.19,3.08)$ & 33 & $1.61^{\mathrm{b}}(1.10,2.36)^{*}$ & 4 & $0.93^{b}(0.34,2.53)$ \\
\hline Eye & 3 & 1.00 & 0 & & 0 & & 3 & $7.30(1.47,36.18)^{\star}$ & 0 & \\
\hline Heart & 41 & 1.00 & 0 & & 0 & & 10 & $1.78(0.89,3.56)$ & 3 & $2.49(0.77,8.08)$ \\
\hline Ear & 34 & 1.00 & 0 & & 0 & & 4 & $0.86(0.30,12.42)$ & 0 & \\
\hline $\begin{array}{l}\text { Cleft lip with or without } \\
\text { palate }\end{array}$ & 11 & 1.00 & 0 & & 0 & & 0 & & 0 & \\
\hline Cleft palate & 6 & 1.00 & 0 & & 0 & & 3 & $3.65(0.91,14.60)$ & 0 & \\
\hline Digestive system & 9 & 1.00 & 0 & & 1 & $6.33(0.80,50.21)$ & 3 & $2.43(0.66,8.99)$ & 1 & $3.77(0.48,29.85)$ \\
\hline $\begin{array}{l}\text { Internal urogenital } \\
\text { system }\end{array}$ & 44 & 1.00 & 1 & $2.02^{\mathrm{c}}(0.27,14.85)$ & 2 & $2.30^{c}(0.55,9.63)$ & 5 & $0.81^{c}(0.32,2.05)$ & 0 & \\
\hline Limbs & 12 & 1.00 & 0 & & 0 & & 1 & $0.61(0.08,4.67)$ & 1 & $2.83(0.37,21.81)$ \\
\hline \multicolumn{11}{|c|}{ Mothers without diseases ${ }^{d}$} \\
\hline Other nervous system & 20 & 1.00 & 1 & $5.30(0.71,39.87)$ & 3 & $8.50(2.51,28.84)^{\star \star *}$ & 3 & $1.16(0.33,3.76)$ & 1 & $1.74(0.23,12.01)$ \\
\hline Neural-tube defects & 4 & 1.00 & 0 & & 0 & & 2 & $3.72(0.68,20.35)$ & 0 & \\
\hline External genital system & 45 & 1.00 & 0 & & 2 & $2.50(0.60,10.38)$ & 6 & $0.99(0.42,2.33)$ & 0 & \\
\hline $\begin{array}{l}\text { Muscloskeletal and } \\
\text { connective tissues }\end{array}$ & 138 & 1.00 & 3 & $2.33(0.73,7.42)$ & 2 & $0.81(0.20,3.29)$ & 28 & $1.52(1.01,2.29)^{*}$ & 3 & $0.75(0.24,2.38)$ \\
\hline Eye & 3 & 1.00 & 0 & & 0 & & 3 & $7.45(1.50,36.96)^{*}$ & 0 & \\
\hline Heart & 38 & 1.00 & 0 & & 0 & & 10 & $1.96(0.98,3.95)$ & 3 & $2.76(0.85,8.99)$ \\
\hline Ear & 33 & 1.00 & 0 & & 0 & & 4 & $0.90(0.32,2.55)$ & 0 & \\
\hline $\begin{array}{l}\text { Cleft lip with or without } \\
\text { palate }\end{array}$ & 9 & 1.00 & 0 & & 0 & & 0 & & 0 & \\
\hline Cleft palate & 5 & 1.00 & 0 & & 0 & & 2 & $2.98(0.58,15.37)$ & 0 & \\
\hline Digestive system & 9 & 1.00 & 0 & & 1 & $6.24(0.79,49.51)$ & 3 & $2.48(0.67,9.18)$ & 1 & $3.87(0.49,30.66)$ \\
\hline $\begin{array}{l}\text { Internal urogenital } \\
\text { system }\end{array}$ & 42 & 1.00 & 1 & $2.24^{c}(0.30,16.50)$ & 2 & $2.34^{c}(0.56,9.81)$ & 5 & $0.87^{c}(0.34,2.20)$ & 0 & \\
\hline Limbs & 10 & 1.00 & 0 & & 0 & & 1 & $0.74(0.10,5.82)$ & 1 & $3.49(0.45,27.31)$ \\
\hline a Reference group. & & & & & & & & & & \\
\hline b Adjusted for parity. & & & & & & & & & & \\
\hline c Adjusted for vitamin & pr iron & pplem & & & & & & & & \\
\hline $\begin{array}{l}\mathrm{d} \text { Excluding mothers } \\
* \mathrm{p}<0.05 ; * * \mathrm{p}<0.01 ;\end{array}$ & $\begin{array}{l}\text { ho hac } \\
* * p<\end{array}$ & $\begin{array}{l}\text { aronic } \\
01 .\end{array}$ & eas & $>38^{\circ} \mathrm{C}$ during first & & pertension, diabetes $\mathrm{m}$ & 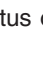 & epartum haemorrhe & & egnancy. \\
\hline
\end{tabular}


pregnant women in Taiwan believed that taking huanglian could help to provide the newborn, and themselves, with a beautiful skin. A previous study showed that pregnant women who gave birth to male infants seemed to experience more skin problems, such as polymorphic eruption or pruritic folliculitis, because of hormonal effects from the fetus. ${ }^{[44]}$ Interestingly, our data show that the sex ratio of all births was higher in the group that took huanglian. The sex ratio was $128: 105$ for the group taking huanglian and the group not taking huanglian, respectively. Thus, we suspect that the women with male fetuses might have had more skin problems that drove them to take huanglian at an earlier stage of pregnancy.

As mentioned previously, traditional wisdom in Taiwan is that An-Tai-Yin prevents spontaneous abortion and indeed the name implies that in Chinese. However, according to an ancient Chinese book, ${ }^{[45]}$ the main effect of An-Tai-Yin is to help pregnant women deliver smoothly. Hence, the most appropriate time to use An-Tai-Yin is in the third trimester. Similarly, advice for using huanglian to improve skin conditions is to take it in the second or third trimester. However, our results showed that $11.4 \%$ and $1.5 \%$ of all pregnant women in the cohort used An-Tai-Yin and huanglian, respectively, during the first trimester. Our data also showed $95 \%$ and $40 \%$ pregnant women who used huanglian and An-Tai-Yin used it without a Chinese physicians' prescription: they bought from Chinese herbal drugstores by themselves or via their family. Clearly, any prevention strategy would need to involve an education programme at the population level.

\section{Strengths and Limitations of the Study}

Prospective 'exposure' data collection during pregnancy, before the outcome of pregnancy is known, is recognised as the best method of gathering reliable data on herbal medicine use during pregnancy. We interviewed our subjects in the third trimester of pregnancy on their use of herbal medicines during the first trimester, before the presence of malformations or the outcome of the pregnancy was known. To reduce recall bias we firstly asked whether or not they used herbal medicines, then asked about frequency. In addition, we used a structured questionnaire administered by well trained interviewers in order to collect data for the study. Thus, we hopefully minimised recall bias with regard to exposure information. There is, of course, the possibility of random misclassification of exposure status, but this would not be expected to produce false-positive findings.

The pregnant women that participated in the study were $\geq 26$ weeks of gestation and only data relating to live born infants were analysed here. Spontaneous abortions or stillborn infants were not included. It is known that both these outcomes are associated with high rates of congenital malformations and we recognise that any early effect of exposure on offspring who die will be missed. These exclusions could result in a selection bias, but not one that produces a false-positive result. Rather, such a bias would result in an underestimation of the true effect. In other words, our study, which includes only live births, may have underestimated the true effect of herbal medicines on the risk of congenital malformations in all pregnancies.

A limitation of this study was that we did not have the information of the newborns' examination if they were not delivered at TMMCH, which was about $16 \%$ of the total. To minimise this effect we linked the national death registration for the period during 1984-2003 and searched National Health Insurance data for critical illnesses and injuries in the children occurring from 1996 to 2000. Because some congenital malformations might not be recognised until the late childhood or even teenage period, the above efforts actually identified 55 additional cases. Thus, the potential selection bias of this study relating to missing data was also minimised to some extent.

Another limitation when exploring the health effects of herbal products is the lack of product standardisation and quality assurance. ${ }^{[46]}$ Besides the direct toxicity of herbal material, issues to consider in any study include contamination by microbes, heavy metals or pesticides, or even adulteration with Western medicines, which may confound 
the potential herbal toxicity. This may have an impact on the effects seen with herbal products.

In addition, the concept of the first trimester is old fashioned now. We calculated the gestational age from the first day of the last menstrual period; thus, pregnant women are not pregnant during the first 2 weeks of gestation. The 3rd and 4th weeks cover the pre- and implantation period of zygotes/ blastocysts. There exists the 'all-or-nothing effect' rule in the first gestational month. It means that the second and third gestational months are considered as critical period for most major congenital malformations caused by environmental hazards. Unfortunately, this study was designed in the 1980s. We did not have the data to separate the gestational weeks.

\section{Conclusion}

We found evidence for a possible link between the use of specific herbal medicines during the first trimester of pregnancy and increased risk of specific groups of congenital malformations. We could not investigate whether the adverse effect related to direct toxicity of herbal medicines, from misuse or contamination, or from uncontrolled confounding. These findings indicate that further research is needed in this area. Nonetheless, we would advise caution regarding their use during the first trimester of pregnancy.

\section{Acknowledgements}

This study was supported by grants (BHP-PHRC-92-4 and DOH93-HP-1702) from the Bureau of Health Promotion, Department of Health, Taiwan.

The authors have no conflicts of interest that are directly relevant to the content of this study.

\section{References}

1. Anthony S, Kateman H, Brand R, et al. Ethnic differences in congenital malformations in the Netherlands: analyses of a 5-year birth cohort. Paediatr Perinat Epidemiol 2005; 19: $135-44$

2. Kalter H. Teratology in the 20th century: environmental causes of congenital malformations in human and how they were established. Neurotoxicol Teratol 2003; 25: 131-282

3. Hoffmann W. Fallout from the Chernobyl nuclear disaster and congenital malformations in Europe. Arch Environ Health 2001; 56: 478-84
4. Mone SM, Gillman MW, Miller TL, et al. Effects of environmental exposures on the cardiovascular system: prenatal period through adolescence. Pediatrics 2004; 113: 1058-69

5. Li SJ, Ford N, Meister K, et al. Increased risk of birth defects among children from multiple births. Birth Defects Res A Clin Mol Teratol 2003; 67: 879-85

6. Becker SM, Al Halees Z, Molina C, et al. Consanguinity and congenital heart disease in Saudi Arabia. Am J Med Genet 2001; 99: 8-13

7. Carmichael SL, Shaw GM. Maternal life event stress and congenital anomalies. Epidemiology 2000; 11: 30-5

8. Rasmussen SA, Moore CA, Paulozzi LJ, et al. Risk for birth defects among premature infants: a population-based study. J Pediatr 2001; 138: 668-73

9. Chuang $\mathrm{CH}$, Lai JN, Wang JD, et al. Prevalence and related factors of Chinese herbal medicine use in pregnant women of Taipei, 1985-1987. Taiwan J Public Health 2005; 24: 335-47

10. Chuang $\mathrm{CH}$, Lai JN, Wang JD, et al. Use of coptidis rhizoma and foetal growth: a follow-up study of 9895 pregnancies. Pharmacoepidemiol Drug Saf 2006; 15: 185-92

11. Goldbeck-Wood S, Dorozynski A, Lie LG, et al. Complementary medicine is booming worldwide. BMJ 1996; 313: 131-3

12. Eisenberg DM, Davis RB, Ettner SL, et al. Trends in alternative medicine use in the United States, 1990-1997: results of a follow-up national survey. JAMA 1998; 280: 1569-75

13. Ni H, Simile C, Hardy AM. Utilization of complementary and alternative medicine by United States adults: results from the 1999 national health interview survey. Med Care 2002; 40: 353-8

14. Nordeng H, Havnen GC. Impact of socio-demographic factors, knowledge and attitude on the use of herbal drugs in pregnancy. Acta Obstet Gynecol Scand 2005; 84: 26-33

15. Nordeng H, Havnen GC. Use of herbal drugs in pregnancy: a survey among 400 Norwegian women. Pharmacoepidemiol Drug Saf 2004; 13: 371-80

16. Tiran $\mathrm{D}$. The use of herbs by pregnant and childbearing women: a risk-benefit assessment. Complement Ther Nurs Midwifery 2003; 9: 176-81

17. Tsui B, Dennehy CE, Tsourounis C. A survey of dietary supplement use during pregnancy at an academic medical center. Am J Obstet Gynecol 2001; 185: 433-7

18. Gibson PS, Powrie R, Star J. Herbal and alternative medicine use during pregnancy: a cross-sectional survey. Obstet Gynecol 2001; 97 Suppl. 1: S44-5

19. Pinn G, Pallett L. Herbal medicine in pregnancy. Complement Ther Nurs Midwifery 2002; 8: 77-80

20. Koren G, Pastuszak A, Ito S. Drugs in pregnancy. N Engl J Med 1998; 338: 1128-37

21. Lacroix I, Damase-Michel C, Lapeyre-Mestre M, et al. Prescription of drugs during pregnancy in France. Lancet 2000; 356: 1735-6

22. Hansan WF, Peacock AE, Yankowitz J. Safe prescribing practices in pregnancy and lactation. J Midwifery Womens Health 2002; 47: 409-21

23. Malm H, Martikainen J, Klaukka T, et al. Prescription of hazardous drugs during pregnancy. Drug Saf 2004; 27: 899-908

24. Andrade SE, Gurwitz JH, Davis RL, et al. Prescription drug use in pregnancy. Am J Obstet Gynecol 2004; 191: 398-407

25. Gallo M, Sarkar M, Au W, et al. Pregnancy outcome following gestational exposure to Echinacea: a prospective controlled study. Arch Intern Med 2000; 160: 3141-3 
26. Simpson M, Parsons M, Greenwood J, et al. Raspberry leaf in pregnancy: its safety and efficacy in labor. J Midwifery Womens Health 2001; 46: 51-9

27. Mabina MH, Pitsoe SB, Mood LJ. The effect of traditional medicines on pregnancy outcome. The King Edward VIII Hospital experience. S Afr Med J 1997; 87: 1008-10

28. Murphy PA. Alternative therapies for nausea and vomiting of pregnancy. Obstet Gynecol 1998; 91: 149-55

29. Conover EA. Over-the-counter products: nonprescription medications, nutraceuticals, and herbal agents. Clin Obstet Gynecol 2002; 45: 89-98

30. Price CJ, George JD, Marr MC, et al. Developmental toxicity evaluation of berberine chloride dehydrate (BCD) in SpragueDawley (CD) rats [abstract]. Teratology 2001; 63: 279

31. Chan LY, Chiu PY, Lau TK. An in-vitro study of ginsenoside Rb1-induced teratogenicity using a whole rat embryo culture model. Hum Reprod 2003; 18: 2166-8

32. Tzeng CR, Yang LL, Chien LW, et al. Effect of traditional Chinese medicine on mouse embryo development. J Taipei Med Coll 1993; 22: 43-6

33. Cosyns JP. Aristolochic acid and Chinese herbs nephropathy: a review of the evidence to date. Drug Saf 2003; 26: 33-48

34. Penson RT, Castro CM, Seiden MV, et al. Complementary, alternative, integrative, or unconventional medicine? Oncologist 2001; 6: 463-73

35. Angell M, Kassirer JP. Alternative medicine: the risks of untested and unregulated remedies. N Engl J Med 1998; 339: 839-41

36. Ko RJ. Adulterants in Asian patent medicines. N Engl J Med 1998; 339: 847

37. Ernst E. Adulteration of Chinese herbal medicines with synthetic drugs: a systemic review. J Intern Med 2002; 252: 107-13

38. World Health Organization. WHO traditional medicine strategy 2002-2005. Geneva: World Health Organization, 2002 (document reference WHO/TRM/2002.1)
39. World Health Organization. General guidelines for methodologies on research and evaluation of traditional medicines. Geneva: World Health Organization, 2000: 27 (document reference WHO/EDM/TRM/2000.1)

40. Eurocat. Eurocat guide 1.2: instructions for the registration of congenital anomalies. Northern Ireland: Eurocat Central Registry, 2002

41. Maldonado G, Greenland S. Simulation study of confounderselection strategies. Am J Epidemiol 1993; 138: 923-36

42. Directorate-General of Budget, Accounting \& Statistics. Manpower statistic annual report, 2004. Census Bureau, Directorate-General of Budget, Accounting \& Statistics (DGBAS), Taiwan, 1985-7 [online] [in Chinese]. Available from URL: http://www.dgbas.gov.tw/census n/four/yrtable4,5,13.xls [Accessed 2005 Jan 1]

43. Chen PC, Fu WL, Wang TR. Congenital malformation statistics in Taiwan, 1993. Taipei, Taiwan: Department of Health, The Excusive Yuan/National Taiwan University Hospital, 1995

44. Vaughan Jones SA, Hern S, Nelson-Piercy C, et al. A prospective study of 200 women with dermatoses of pregnancy correlating clinical findings with hormonal and immunopathological profiles. Br J Dermatol 1999; 141: 71-81

45. Fu Q-Z, Yang S-Z, Liu D-W. Fu Qing-zhus gynecology. Boulder, (CO): Blue Poppy Press, 1999

46. Wen KC. The turnover rate of marker constituents in Chinese herbal medicines. J Food Drug Anal 2000; 8: 270-7

Correspondence and offprints: Dr Pau-Chung Chen, Institute of Occupational Medicine and Industrial Hygiene, National Taiwan University College of Public Health, 17 Syujhou Road, Taipei 100, Taiwan.

E-mail: pchen@ntu.edu.tw 
Copyright of Drug Safety is the property of ADIS International Limited and its content may not be copied or emailed to multiple sites or posted to a listserv without the copyright holder's express written permission. However, users may print, download, or email articles for individual use. 